\title{
The Sensitivity of Global Climate Model Simulations to the Representation of Soil Moisture Heterogeneity
}

\author{
N. GEDney And P. M. CoX \\ Hadley Centre, Met Office, Bracknell, Berkshire, United Kingdom
}

(Manuscript received 19 December 2002, in final form 18 June 2003)

\begin{abstract}
Improving the treatment of subgrid-scale soil moisture variations is recognized as a priority for the next generation of land surface schemes. Here, the impact of an improved representation of subgrid-scale soil moisture heterogeneity on global climate model (GCM) simulations of current and future climates is carried out using Version three of the Hadley Centre Atmospheric Climate Model (HadAM3) coupled to the Met Office Surface Exchange Scheme (MOSES). MOSES was adapted to make use of the rainfall runoff model TOPMODEL algorithms, which relate the local water table depth to the grid box mean water table depth, assuming that subgrid-scale topography is the primary cause of soil moisture heterogeneity. This approach was also applied to produce a novel model for wetland area, which can ultimately be used to interactively model methane emissions from wetlands. The modified scheme was validated offline by forcing with near-surface Global Soil Wetness Project (GSWP) data, and online within the HadAM3 global climate model. In both cases it was found to improve the present-day simulation of runoff and produce realistic distributions of global wetland area. (Precipitation was also improved in the online simulation.) The new scheme results in substantial differences in the modeled sensitivity of runoff to climate change, with implications for the modeling of hydrological impacts.
\end{abstract}

\section{Introduction}

The historical development of GCM land surface schemes (LSSs) has tended to focus on the vertical transfer of water (and heat) through the soil and canopy. The evaporative fluxes from the bare soil and the wet and dry parts of the canopy are generally modeled separately, and vertical transfers of water and moisture in the soil are explicitly modeled using multilayer models. The Met Office Surface Exchange Scheme, (MOSES; Cox et al. 1999), has a typical structure for this generation of LSSs, using four soil layers in the vertical with depths chosen to capture important soil temperature cycles (for MOSES the default thicknesses from the surface downwards are $0.1,0.25,0.65$, and $2.0 \mathrm{~m}$ ). Recognizing the strong nonlinearity of the Richards' equation, some GCM land surface modelers have recently increased the vertical resolution of their soil models (de Rosnay et al. 2002) to further improve the accuracy with which vertical flows can be captured.

This continuing improvement in the representation of vertical processes is in stark contrast to progress on the representation of horizontal heterogeneity, such that the latter is now seen as a priority for the next generation

Corresponding author address: Dr. Nicola Gedney, JCHMR, Met Office, Maclean Building, Crowmarsh Gifford, Wallingford OX10 8BB, United Kingdom.

E-mail: nicola.gedney@metoffice.com of LSSs (Polcher et al. 2000). Current LSSs are applied directly at the GCM resolution, which is much too coarse to explicitly represent important aspects of land surface heterogeneity. Surface fluxes tend to be calculated from the grid box mean soil water stores, without taking account of subgrid variations in soil moisture that can significantly modify grid box mean fluxes (Stieglitz et al. 1997).

In reality, even within a single catchment there can be large variations of soil moisture due to a number of factors, including vegetation, soil properties, and topography. Various LSSs parameterizations for heterogeneity due to vegetation (e.g., MOSAIC, Koster and Suarez 1992), topography (e.g., Dumenil and Todini 1992; Stieglitz et al. 1997) and soil properties (e.g., Boone and Wetzel 1999) have been developed. Overland flow usually occurs either when the rainfall rate exceeds the soil saturated hydraulic conductivity (Hortonian runoff) or when the soil surface becomes saturated from beneath (Dunne runoff). If this soil moisture variability is not modeled then localized saturated areas are not represented. Such omissions may affect the accuracy of the simulated hydrological partitioning within the climate model. Indeed most of the differences in hydrological behavior in the LSSs studied in Gedney et al. (2000) are due to runoff formulations, rather than evaporation.

In common with other GCM LSSs, MOSES (Cox et al. 1999; Essery et al. 2003) has a relatively detailed 
depiction of the grid box mean fluxes, but no subgridscale horizontal soil moisture variability. Up to five different vegetation tiles in each gridbox are allowed, but each tile shares the same gridbox mean soil moisture store. Compared to the other LSSs in Gedney et al. (2000), MOSES tends to produce comparable evaporation, but low runoff, for a given soil moisture stress.

To start to address this limitation we have considered only the issue of topography-driven soil moisture heterogeneity. Various approaches for its implicit or explicit inclusion are currently available, such as: Probability Distributed Moisture model (PDM; Moore 1985), Variable Infiltration Capacity model (VIC; Wood et al. 1992), Arno (Dumenil and Todini 1992) and TOPMODEL (Beven 1986; Beven and Kirkby 1979). The first three models assume similar probability distribution functions to describe subgrid-scale soil moisture capacity. TOPMODEL encompasses a prognostic water table. It is based on the hypothesis that topography is the primary cause of water table variability within many catchments. Information on subgrid topography variation and the height of the mean water table are used to predict the extent of low-land saturation.

We chose to focus on the effect of topography on soil moisture and on the TOPMODEL methodology in particular, because it enables us to explicitly model wetlands interactively, and therefore potentially model trace-gas fluxes. In addition, TOPMODEL can also be extended to include some aspects of soil property heterogeneity (Sivapalan et al. 1987).

In order to apply the TOPMODEL idea, we have coupled a reduced form of TOPMODEL to MOSES. The application of this approach at the GCM grid scale assumes that relationships between subgrid-scale soil moisture and topography hold even over areas that are much larger than a typical river catchment. This assumption is supported by the tendency for topography to be self-similar (such that large-scale and small-scale variations can be related), but ultimately it must be treated as a pragmatic working hypothesis at this stage. We also neglect subgrid-scale variations in soil parameters at this stage.

In section 2 we give an overview of the MOSES LSS, the version of TOPMODEL described in Sivapalan et al. (1987) and a more detailed description of our extension to TOPMODEL that enables us to estimate wetland area and allows some of the standard TOPMODEL assumptions to be relaxed. Section 3 describes the setup of the model validation experiments. Both online (GCM) and offline (LSS is forced from observations/ analyses) studies are carried out. Time-slice climate change experiments are also described here, whereby the effect of the modified LSS on the sensitivity to climate change is investigated. Section 4 analyzes the results of these simulations. Section 5 describes the major conclusions of this study and highlights areas that require further investigation.

\section{Overview of the models}

\section{a. Overview of MOSES}

A detailed description of the standard MOSES model can be found in Cox et al. (1999) and Essery et al. (2003). A summary of the surface and subsurface runoff parameterizations is given here. The local precipitation rates are assumed to fall on a fraction of each grid box ( 0.5 for large-scale rain and 0.1 for convective rain), and to have local intensities in the wet area that are exponentially distributed. As precipitation hits the canopy a portion is captured, with the remainder falling to the surface. This canopy throughfall infiltrates the soil at a rate of the saturated hydraulic conductivity multiplied by an enhancement factor, which is dependent on the presence of vegetation. If the local throughfall rate is greater than the infiltration rate, the surplus is lost as Hortonian surface runoff. Drainage through the soil is calculated using a discretized version of the Richards' equations with four soil layers (thicknesses 0.1, 0.25, $0.65,2.0 \mathrm{~m})$. Hydraulic conductivity and suction are calculated using Clapp-Hornberger characteristic curves (Clapp and Hornberger 1978).

In the online studies MOSES is run in the host GCM HadAM3 (Pope et al. 2000). HadAM3 has performed well in the Atmospheric Model Intercomparison Project (AMIP) producing realistic contemporary patterns of temperature and precipitation. In addition HadCM3 is one of few coupled ocean-atmosphere GCMs that can produce reasonable patterns of sea surface temperatures without the need for flux adjustments (Houghton et al. 2001). Its climate sensitivity is $3.3 \mathrm{~K}$ (midrange) (Houghton et al. 2001).

\section{b. Extension of MOSES}

In order to parameterize groundwater flow $Q$, a deep water store (thickness $12 \mathrm{~m}$ ) is added beneath the standard four-layer soil model of MOSES. The grid box mean water table depth $\overline{z_{w}}$ is modeled prognostically within this deep store:

$$
\rho \theta_{\mathrm{sat}} \frac{d \overline{z_{w}}}{d t}=I_{5}-Q_{5}
$$

where $\rho$ is the density of water and $\theta_{\text {sat }}$ is the saturated volumetric water content. Here, $I_{i}$ and $Q_{i}$ are the infiltration into and baseflow out of the $i$ th layer respectively (see Fig. 1). If this layer saturates, the water table depth is then diagnosed to be within the deepest soil layer that is not saturated. In addition to the vertical drainage fluxes between soil layers, base flow $Q_{i}$ occurs out of any layer that is below or contains the top of the water table:

$$
\Delta z_{i} \rho \frac{d \theta_{i}}{d t}=I_{i}-E_{i}-Q_{i}
$$

where $\Delta z_{i}$ is the thickness of the soil layer, $\theta_{i}$ volumetric 


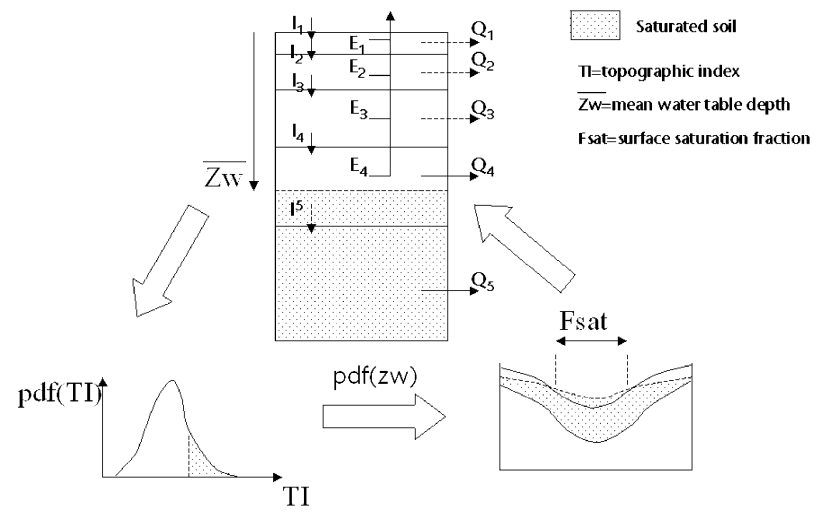

FIG. 1. Schematic diagram of the combined MOSES-TOPMODEL approach.

fraction water content, and $E_{i}$ is the extraction due to evaporation out of the $i$ th soil layer. The partitioning of the baseflow out of a layer is based on the relative amount of water table within that layer.

Having calculated the grid box mean water table depth, an estimate of its spatial variability is required to predict the extent of saturation at the surface, and hence the amount of Dunne runoff. The basic theory from which this is derived is described in detail in Sivapalan et al. (1987). A brief overview is given next.

\section{c. Overview of TOPMODEL}

If the water table within a catchment is assumed to be in steady state, then a general solution for the local water table depth $z_{\mathrm{wl}}$ relative to the mean may be obtained if the saturated conductivity $K_{\text {sat }}$ decreases exponentially with depth as follows:

$$
K_{\text {sat }}(z)=K_{\text {sat }}(0) \exp (-f z),
$$

where $K_{\text {sat }}(0)$ is the saturated conductivity at the surface and $f$ is an exponent describing the reduction of saturated conductivity with depth. [Beven (1982) cites many examples where this is a reasonable assumption.] by

The local downslope flow, $q_{l}$, at any point is given

$$
q_{l}=T\left(z_{\mathrm{wl}}\right) \tan \beta_{l},
$$

where $\beta_{l}$ is the local topographic gradient, and the local transmissivity $T\left(z_{\mathrm{wl}}\right)$ is given by integrating Eq. (3) vertically through the saturated zone, from the local water table depth, $z_{\mathrm{wl}}$, to the bottom of the profile, $z_{\mathrm{wmax}}$ :

$$
T\left(z_{\mathrm{wl}}\right)=\int_{z_{\mathrm{wl}}}^{z_{\mathrm{wmax}}} K_{\mathrm{sat}}(z) d z .
$$

TOPMODEL assumes a quasi-equilibrium state in which the local downslope flow, $q_{l}$, is balanced by a spatially, uniform recharge rate $R$ from a local upslope area, $a_{l}\left(q_{l}=a_{l} R\right)$. Integrating over the catchment yields a relationship between the local water table depth, $z_{\mathrm{wl}}$, and the grid box mean water table depth, $\overline{z_{w}}$ :

$$
f\left\{z_{\mathrm{wl}}-\overline{z_{w}}\right\}=\Lambda_{l}-\bar{\Lambda},
$$

where $\Lambda_{l}$ is the local "topographic index" given by

$$
\Lambda_{l}=\ln \left(\frac{a_{l}}{\tan \beta_{l}}\right)
$$

and $\bar{\Lambda}$ is the area average of $\Lambda_{l}$ over the catchment area. Equation (6) is especially valuable because it relates the local moisture status (as given by $z_{\mathrm{wl}}$ ) to the catchment mean moisture status (as represented by $\overline{z_{w}}$ ) based purely on the subgrid-scale variations in topography. Larger than average values of $\Lambda_{l}$ are indicative of areas with a higher than average water table (e.g., valley bottoms), while lower than average $\Lambda_{l}$ is representative of a deeper than average water table (e.g., at hilltops). Most importantly for our application, this equation can be integrated to yield the fraction of the grid box that is saturated at the surface (i.e., a water table at or above the surface), and which will therefore generate saturation excess (or Dunne) runoff.

Furthermore, an equation for the catchment-averaged baseflow per unit area, $Q$, can be derived by combining Eqs. (7) and (4):

$$
q_{l}=a_{l} T\left(z_{\mathrm{wl}}\right) \exp (-\Lambda)
$$

and then integrating

$$
Q=T\left(\overline{z_{w}}\right) \exp (-\bar{\Lambda})
$$

\section{d. Extension of TOPMODEL}

We have extended the Sivapalan et al. (1987) formulation to cover any generalized function of $K_{\text {sat }}$ with depth, relaxing the assumption that $K_{\text {sat }}$ varies exponentially throughout the profile. In reality, soil parameters vary in the vertical in complex ways, which may not be well approximated by the exponential function with depth. Instead we only assume that exponential decay occurs within the saturated zone beneath the fourlayer soil model of MOSES. In principle this allows observed soil parameter profiles to be used in the top $3 \mathrm{~m}$ of the profile, although for simplicity we have assumed uniform $K_{\text {sat }}$ in the sensitivity studies presented here. This allows for a clean diagnosis of the impacts of TOPMODEL, without the additional effects of assuming saturated hydraulic conductivity variation in the four MOSES soil layers. Beneath the MOSES soil model $K_{\text {sat }}$ decays in the standard TOPMODEL manner, as given by Eq. (3), with a value of $f=0.5 \mathrm{~m}^{-1}$. (A range of values were tested from $0.25-2 \mathrm{~m}^{-1}$. The globally averaged, annual mean of runoff $Y$ to precipitation $P$ ratio $(Y / P)$ was found to be fairly insensitive over this range. This is in part because this parameter does not affect the conductivity within the soil model itself. The value of $f=0.5 \mathrm{~m}^{-1}$ minimized the annual mean $Y / P$ rms errors in the offline global mean runoff simulation described in section 3.)

To make further progress we assume that local areas 
within the grid box where the local topographic index $\lambda_{l}$ equals that of the grid box mean, correspond to areas of grid box mean water table depth. Using the quasiequilibrium assumption described in section $2 \mathrm{c}, q_{l} / a_{l}$ is assumed to be constant. Hence the local water table depth $z_{\mathrm{wl}}$ is related to the local topographic index by

$$
T\left(z_{\mathrm{wl}}\right) \exp \left(-\Lambda_{l}\right)=T\left(\overline{z_{w}}\right) \exp (-\bar{\Lambda})
$$

and therefore

$$
\ln \left[\frac{T\left(z_{\mathrm{wl}}\right)}{T\left(\overline{z_{w}}\right)}\right]=\Lambda_{l}-\bar{\Lambda} .
$$

We have analyzed the high-resolution global topographic index dataset of Verdin and Jenson (1996) to produce a statistical distribution of the subgrid-scale topographic index for each climate model grid box. This probability distribution function is assumed to take the form of a gamma distribution as in Sivapalan et al. (1987). This dataset is at a $1 \mathrm{~km} \times 1 \mathrm{~km}$ resolution, which is too low to be strictly valid for the TOPMODEL concept, as it cannot resolve hills and valleys. However, topography tends to exhibit self-similarity (Brown and Scholz 1985) so we use this as a first approximation until a more detailed dataset is available at the global scale.

From Eq. (11) the local water table is at or above the surface when the local topographic index is greater than a critical value $\Lambda_{\mathrm{cr}}^{\min }$, which is dependent on the current mean water table depth at a given grid box (see Fig. 1), such that

$$
\Lambda_{\mathrm{cr}}^{\min }=\ln \left[\frac{T(0)}{T\left(\overline{z_{w}}\right)}\right]+\bar{\Lambda} .
$$

The fraction of the surface that is saturated in a grid box, $F_{s}$ is then given by the relative area where $\Lambda_{l} \geq$ $\Lambda_{\mathrm{cr}}^{\min }$ over the whole grid box (see Fig. 1). Under partially saturated conditions the grid box mean net infiltration $I_{1}$ into the top soil layer is therefore reduced by

$$
I_{1}=\left(1-F_{s}\right) I_{H 1},
$$

where $I_{H 1}$ is the infiltration rate into the soil if only Hortonian runoff is considered.

In addition to the surface saturation fraction, we also require an estimate of actual wetland extent, as this can be validated against observations and can be used in the interactive modeling of methane emissions from wetlands. Wetland is limited to areas of stagnant water. However, if the water table rises well above the surface, this can be viewed as indicative of streamflow. We therefore define a maximum critical topographic index parameter $\Lambda_{\mathrm{cr}}^{\max }$ to calibrate the wetland area with observations. It is assumed that where the local topographic index is greater than the critical value $\left(\Lambda_{l}>\Lambda_{\mathrm{cr}}^{\max }\right)$ the water table is too deep and results in significant flow. Hence in a given grid box, a local point is assumed to be wetland only when

$$
\Lambda_{\mathrm{cr}}^{\max } \geq \Lambda \geq \Lambda_{\mathrm{cr}}^{\min },
$$

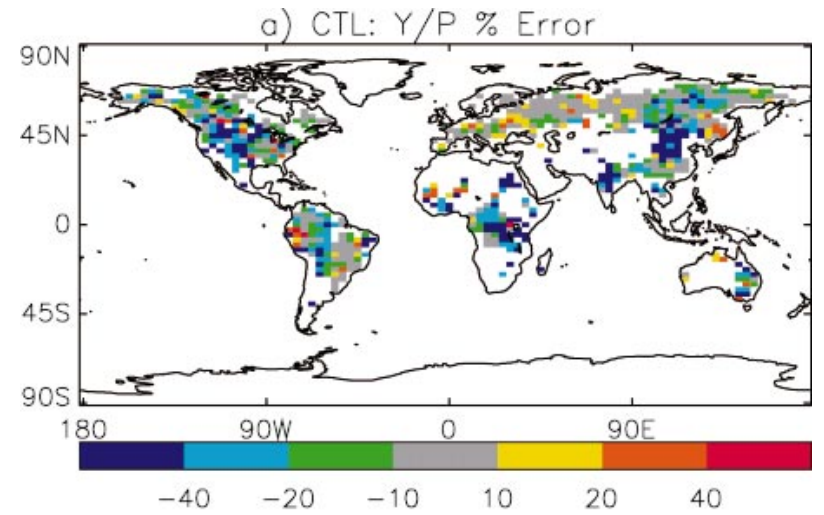

b) LSH-CTL: Absolute Change $Y / P \%$ Error

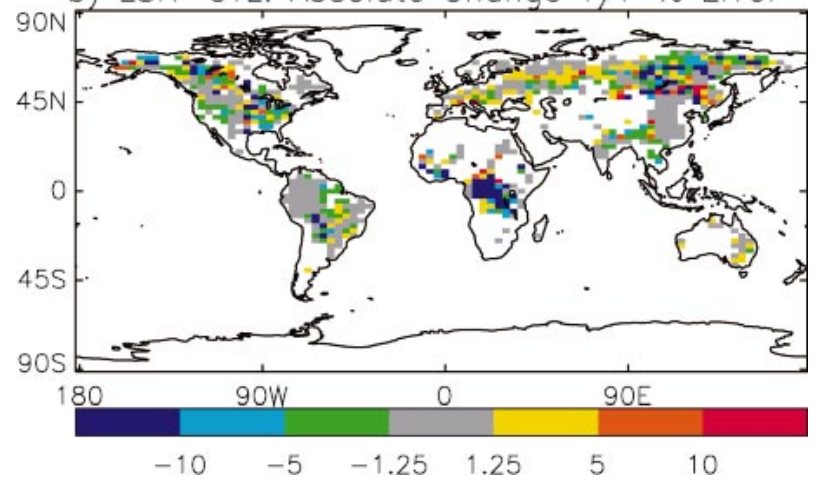

FIG. 2. The impact of including the new large-scale hydrology (LSH) parameterization on the offline simulation $Y / P$. [The precipitation and runoff observed datasets used are Xie and Arkin (1997) and GRDC Fekete et al. (2002), respectively. The blank areas indicate where there is no runoff data.] (a) Percentage error in $Y / P$ for the standard MOSES simulation (CTL). Green/blue colors signify an underestimate and orange/red an overestimate. (b) Absolute change in percentage error in $Y / P$ within the LSH simulation. Green/blue colors signify an improvement, orange/red signify a deterioration. Please note the change in scale between (a) and (b).

where the global parameter $\Lambda_{\mathrm{cr}}^{\max }$ (fixed in time as well as space) is chosen to give the best agreement with observations. [The value was calibrated so that the modeled zonal mean wetland best fitted the observations of Aselmann and Crutzen (1989) in the offline studies described in section 3. Without the inclusion of this parameter the model tends to overestimate the wetland extent. The zonal mean rms error is halved with the inclusion of this calibrated parameter.]

However, under partially frozen conditions one would not expect significant flow velocity. In order to account for this, the extent of soil freezing at the mean water table depth is used to calculate an effective wetland fraction:

$$
F_{\text {wet }}^{\text {eff }}=\frac{\theta_{u}}{\theta_{u}+\theta_{f}} F_{\text {wet }}+\frac{\theta_{f}}{\theta_{u}+\theta_{f}} F_{\text {sat }},
$$

where $\theta_{u} \theta_{f}$ are the frozen and unfrozen soil moisture fractions, respectively, at the mean water table depth. 
TABLE 1. Offline simulations of annually averaged, mean runoff/ precipitation ratio and the rms errors. (The values are based on calculations from all land regions in the GRDC dataset.)

\begin{tabular}{lcc}
\hline \hline & $Y / P$ & Rms error \\
& & $Y / P$ \\
\hline OBS & 0.380 & - \\
CTL & 0.239 & 0.207 \\
LSH & 0.284 & 0.197 \\
\hline
\end{tabular}

\section{Experiments}

We assess the standard version of the MOSES land surface scheme against MOSES modified to include the TOPMODEL-based large-scale hydrology parameterization (LSH), both offline and online within the climate model. Offline studies have the advantage of using realistic near-surface forcing data, thereby allowing a direct assessment of the LSS performance against observations.

The setup of the LSS scheme in both on- and offline studies is similar. The land soil temperature and moisture is initialized from monthly means from GCM output. The water table field is initialized such that, if the fourth soil layer is not saturated, the drainage from the fourth soil layer is in equilibrium with the baseflow out of the deep groundwater (fifth) layer. If the fourth layer is saturated, then the mean water table is diagnosed to be in the deepest soil layer that is unsaturated. The spatial resolution of the model is $2.5^{\circ}$ latitude $\times 3.75^{\circ}$ longitude in both cases. Both models are spun up until there are no discernible trends in the annual mean soil moisture, temperature, and water table fields.

Data from the Global Soil Wetness Project (GSWP Dirmeyer et al. 1999) for years 1987 and 1988 are used for the offline study. The GSWP data are a combination of observations and analyses at the 6-hourly timescale. Each LSS is spun up by repeatedly forcing it with the 1987 data until equilibrium is reached. The models are then run from the spunup state for two more years with the 1987 and then the 1988 forcing data. The output from the final $2 \mathrm{yr}$ is compared with observations.

For both LSSs, two time-slice experiments are carried out, consisting of a $1 \times \mathrm{CO}_{2}$ and a $2 \times \mathrm{CO}_{2}$ run (defined as 323 ppmv and 646 ppmv of $\mathrm{CO}_{2}$, respectively). This and other aspects of the GCM experimental design were chosen for consistency with previous published studies (e.g., Gedney et al. 2000). The $1 \times \mathrm{CO}_{2}$ sea surface temperature and sea ice fields are derived as monthly means over the first AMIP period (Gates 1992). The temperature and sea ice changes produced by the Hadley Centre transient climate change run (Mitchell et al. 1995) are applied to the AMIP climatological fields to produce the boundary conditions for the $2 \times \mathrm{CO}_{2}$ timeslice simulations.

The online study is carried out with the host atmosphere-only Met Office GCM HadAM3. The GCM atmosphere state is initialized from the output of a long GCM run with the standard MOSES LSS incorporated.
TABLE 2. Offline simulation annual mean (1987-88), basin-averaged runoff compared to UNESCO (1971) observations. (Those basins with an improved simulation with LSH have a + superscript). (Basins are in descending order of area.)

\begin{tabular}{|c|c|c|c|c|}
\hline River basin & $\begin{array}{l}\text { OBS flow } \\
\text { mm day }{ }^{-1}\end{array}$ & $\begin{array}{c}\text { CTRL flow } \\
\mathrm{mm} \mathrm{day}^{-1}\end{array}$ & $\begin{array}{c}\text { CTRL-OBS } \\
\mathrm{mm} \mathrm{day}^{-1}\end{array}$ & $\begin{array}{l}\text { LSH-OBS } \\
\text { mm day }{ }^{-1}\end{array}$ \\
\hline Amazon & 2.89 & 1.95 & -0.94 & -0.94 \\
\hline Zaire $^{+}$ & 1.00 & 0.30 & -0.70 & -0.22 \\
\hline Mississippi $^{+}$ & 0.46 & 0.22 & -0.24 & -0.19 \\
\hline $\mathrm{Ob}$ & 0.37 & 0.44 & 0.07 & 0.11 \\
\hline Yenisei $^{+}$ & 0.63 & 0.59 & -0.04 & 0.00 \\
\hline Lena $^{+}$ & 0.58 & 0.42 & -0.16 & -0.11 \\
\hline Parana & 0.74 & 0.94 & 0.20 & 0.27 \\
\hline Nile & 0.13 & 0.15 & 0.02 & 0.20 \\
\hline Amur $^{+}$ & 0.48 & 0.31 & -0.17 & -0.09 \\
\hline Chang-Yiang & 1.46 & 1.57 & 0.11 & 0.12 \\
\hline Ganges $+\mathrm{B}^{+}$ & 1.83 & 0.78 & -1.05 & -1.00 \\
\hline Mackenzie $^{+}$ & 0.50 & 0.28 & -0.22 & -0.17 \\
\hline Volga $^{+}$ & 0.51 & 0.42 & -0.09 & -0.05 \\
\hline Nelson $^{+}$ & 0.21 & 0.12 & -0.09 & 0.04 \\
\hline Huang $\mathrm{Ho}^{+}$ & 0.13 & 0.03 & -0.10 & -0.09 \\
\hline Murray & 0.02 & 0.02 & 0.00 & 0.00 \\
\hline Orange & 0.02 & 0.06 & 0.04 & 0.06 \\
\hline Orinoco $^{+}$ & 3.20 & 1.69 & -1.51 & -1.49 \\
\hline Indus & 0.41 & 0.28 & -0.14 & -0.14 \\
\hline Danube & 0.69 & 1.00 & 0.31 & 0.45 \\
\hline Yukon $^{+}$ & 0.70 & 0.33 & -0.37 & -0.30 \\
\hline Mekong $^{+}$ & 1.90 & 0.43 & -1.47 & -1.31 \\
\hline Columbia & 0.76 & 0.17 & -0.59 & -0.59 \\
\hline $\mathrm{Sao} \mathrm{Franciso}^{+}$ & 0.40 & 0.56 & 0.16 & 0.06 \\
\hline Kolyma $^{+}$ & 0.53 & 0.37 & -0.16 & -0.10 \\
\hline Niger $^{+}$ & 1.08 & 0.87 & -0.21 & 0.04 \\
\hline All basins ${ }^{+}$ & 0.96 & 0.65 & -0.31 & -0.22 \\
\hline
\end{tabular}

In each run the climate model is spun up for a minimum of $5 \mathrm{yr}$ and is then run on for a further $10 \mathrm{yr}$. Since climatological sea surface boundary conditions are prescribed, and the GCM runs are long compared to typical modes of atmospheric variability, it was not considered necessary to carry out expensive initial-condition ensembles. Instead statistical analyses (Student's $t$ tests) are used to assess the significance of changes in the long-term means.

\section{Results \\ a. Offline validation}

Figure 2a compares the control offline run using the standard MOSES LSS (CTL) with the observed ratio of annual mean runoff [Fekete et al. (2002), The Global Runoff Data Centre, Koblenz, Germany] to precipitation (Xie and Arkin 1997). (We use this ratio so that when analyzing the GCM simulations we can reduce the influence of the error in the GCM simulation of precipitation on that of the runoff.)

Figure $2 \mathrm{a}$ shows the percentage error in the control CTL run. In a majority of regions, there is a systematic underestimation of runoff. This is to be expected, given the lack of soil moisture heterogeneity in the LSS. Figure $2 \mathrm{~b}$ gives the absolute change in percentage errors between the CTL and LSH simulations. (Green and blue 


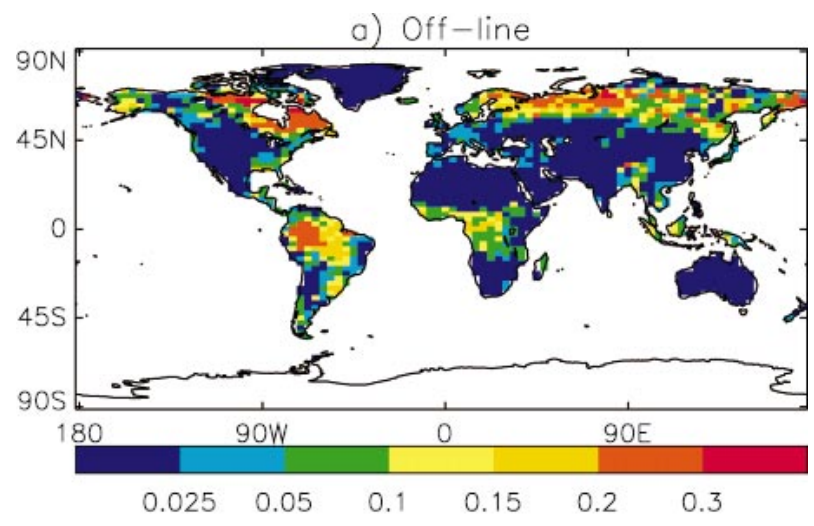

b) Online

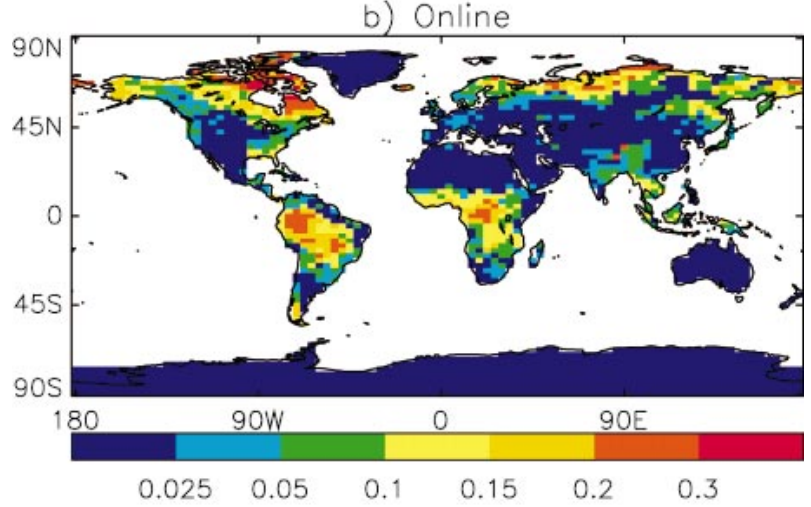

c) Observed: Azelmann and Crutzen

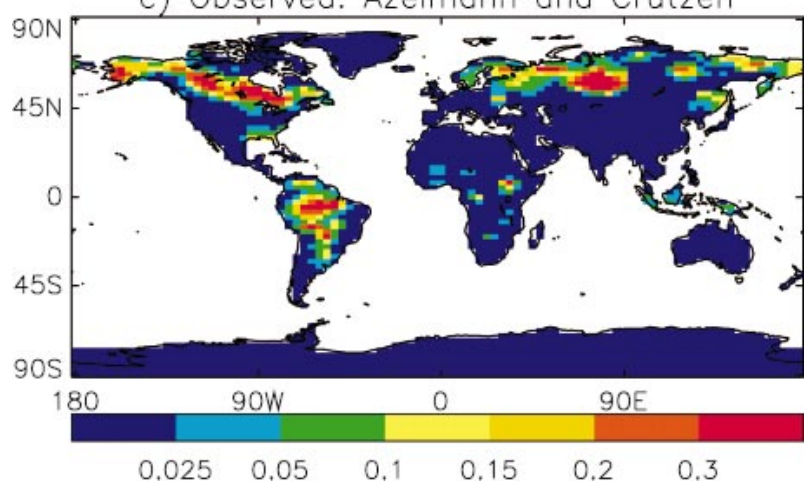

FIG. 3. The modeled, annual mean, natural wetland fraction compared to the observations of natural wetland area. (a), (b) The offline and online modeled natural wetland fraction, respectively. (c) The observations of Aselmann and Crutzen (1989).

signify an improvement of the LSH simulation over the CTL, and orange and red a degradation in performance.) Over most regions the LSH scheme increases runoff and therefore produces an improvement. Table 1 shows the resulting reduction in the annually averaged, land mean biases and root-mean-square (rms) errors. The overall reduction in bias is from about $37 \%$ to $25 \%$ and $\mathrm{rms}$ is improved by roughly $5 \%$.

Table 2 gives a breakdown of the modeled annual mean flow for the largest basins and compares them to the UNESCO (1971) observations. You can again see

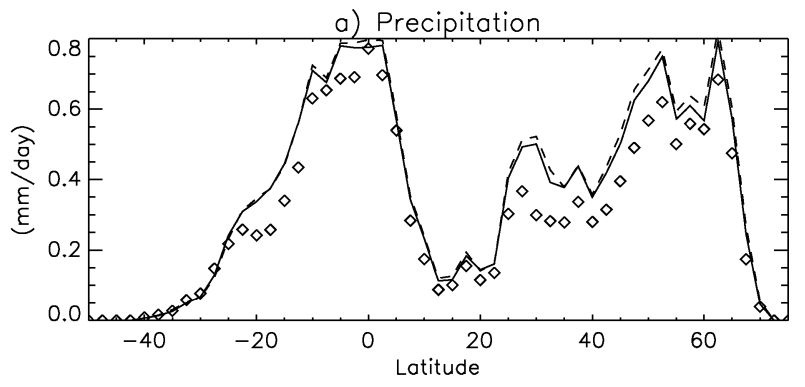

b) Total Runoff

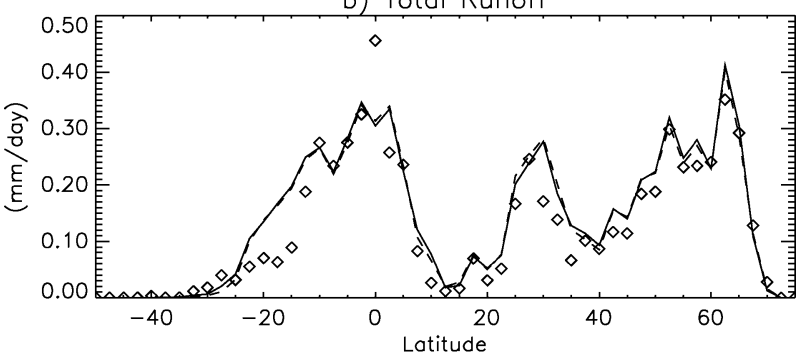

c) Surface Runoff

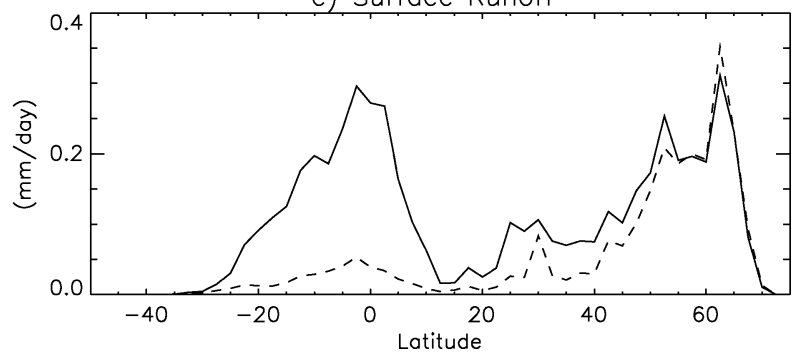

FIG. 4. The $1 \times \mathrm{CO}_{2}$ annual average zonal mean over land simulations: (a) precipitation, (b) runoff, (c) surface runoff. LSH (solid line); CTL (dashed line); observations (diamonds).

the tendency for the standard MOSES model to underestimate runoff. This tendency is generally reduced with the LSH model, overall by about a third with this dataset. Out of the 26 basins assessed, 16 show an improvement, and only 6 are worse.

We have also assessed the offline modeled natural wetland fraction, where this is defined as the total wetland fraction over the nonagricultural fraction of the grid box only. There is generally a good correspondence between the model (Fig. 3a) and the Aselmann and Crutzen (1989) observed dataset of natural wetland fraction (Fig. $3 \mathrm{c})$, but the model tends to underestimate the magnitude at high latitudes. This could be because we currently neglect the effect of the near-surface, very high soil carbon content in peat lands at these latitudes on the soil properties. Given the very high compressibility of this soil, it is more important that the porosity, and therefore the saturated hydraulic conductivity should both decrease with depth.

\section{b. Online validation}

We now assess the hydrological budget online within the GCM to see how the two LSSs behave in the climate 
a) CTL: $Y / P \%$ Error

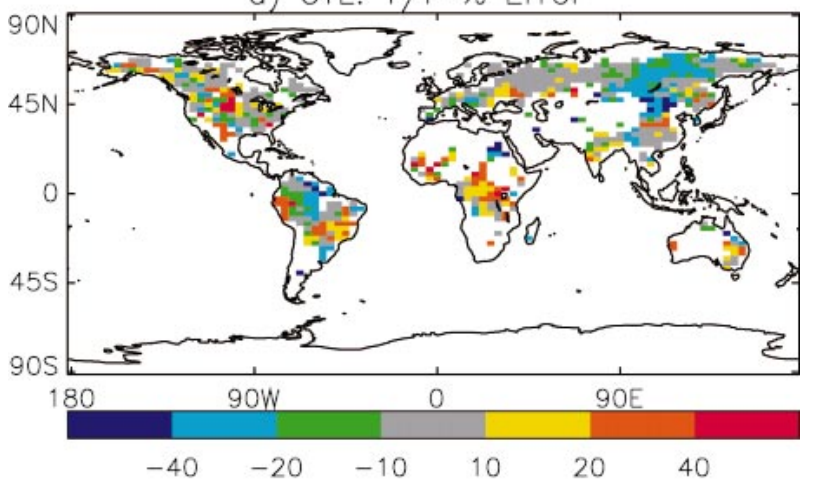

b) LSH-CTL: Absolute Change $Y / P$ \% Error

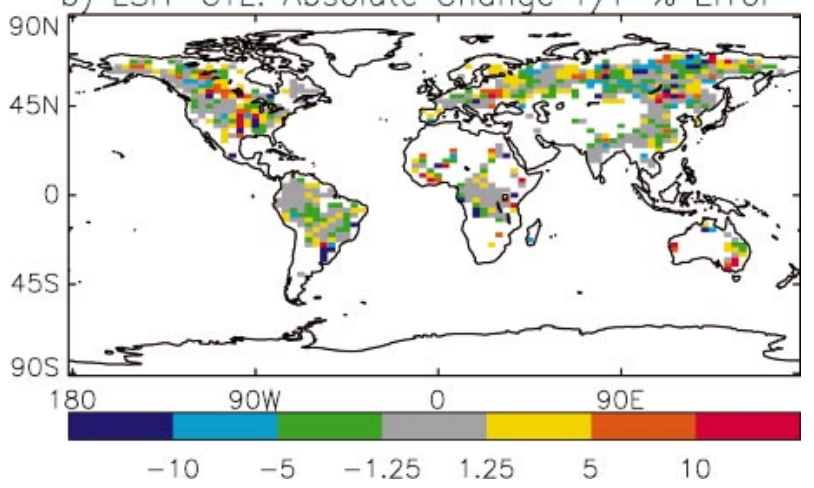

FIG. 5. As in Fig. 2 but for the GCM simulation.

model. Figure 4 shows the land-averaged, zonal means of precipitation, total runoff, and surface runoff under the simulated present-day climate. HadAM3 has a tendency to overestimate precipitation (Fig. 4a). However this error is consistently reduced with the inclusion of the LSH scheme. The bias and rms error in precipitation are both improved (Table 3). (However, based on a Student's $t$ test, this is only statistically significant at the 95\% level over $1 \%$ of grid boxes.) This tendency to overestimate precipitation, is reflected in the general overproduction of total runoff with both LSSs (Fig. 4b). There is no consistent difference in the zonal mean runoff between the two LSS schemes. The positive bias in land-averaged runoff increases slightly with the LSH scheme, however, the rms error is slightly reduced (Table 3). (The runoff changes are found to be statistically significant at the $95 \%$ level over $41 \%$ of grid boxes.) Even though the total runoff is very similar, the separate a) Precipitation: $2 \times \mathrm{CO} 2-1 \times \mathrm{CO} 2$

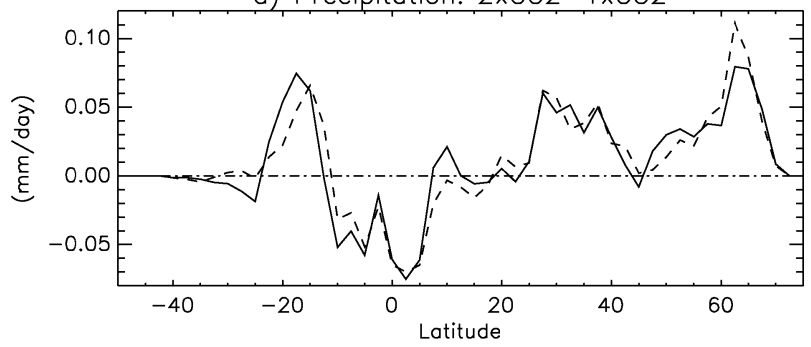

b) Total Runoff: $2 \times \mathrm{CO} 2-1 \times \mathrm{CO} 2$

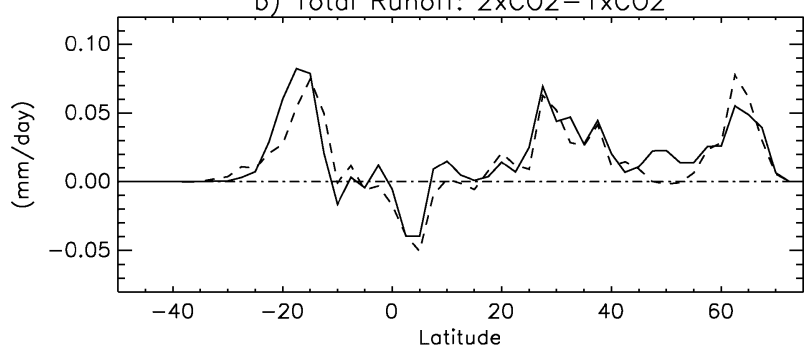

c) Surface Runoff: $2 \times \mathrm{CO} 2-1 \times \mathrm{CO} 2$

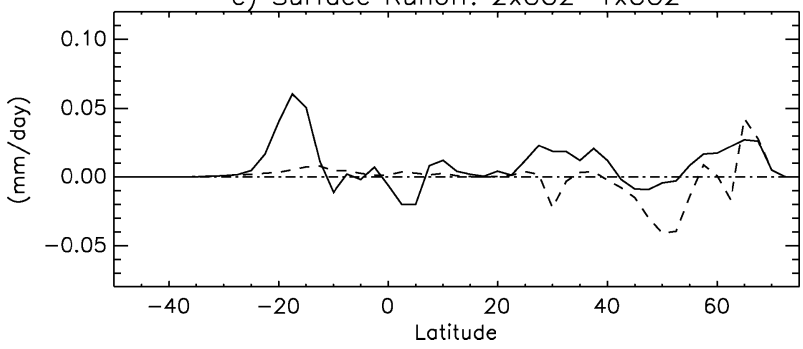

FIG. 6. The $2 \times \mathrm{CO}_{2}-1 \times \mathrm{CO}_{2}$ annual average zonal mean over land simulations: (a) precipitation, (b) runoff, (c) surface runoff. LSH (solid line); CTL (dashed line).

components are very different. Surface runoff dominates in the LSH scheme, whereas the CTL version produces negligible amounts over unfrozen ground (Fig. $4 c)$.

A fairer assessment of the two schemes is made by repeating the $Y / P$ comparison. Looking at the CTL simulation of annual mean runoff to precipitation ratios, there are differences between the online (Fig. 5a) and offline (Fig. 2a) studies. These are mainly the result of errors in the simulated precipitation. In particular there are more areas where $Y / P$ is overestimated in the online study, for example, central Africa, much of eastern Brazil. If this rainfall bias is large enough, it results in a significant overestimate of runoff and therefore $Y / P$.

TABLE 3. As in Table 1, but for the GCM simulation. (The percentage number of points where the statistical significance level is greater than $95 \%$ is given in brackets after the LSH annual mean values.)

\begin{tabular}{llccccc}
\hline \hline & & Rms error & & & & \\
& $Y / \mathrm{P}$ & $Y / \mathrm{P}$ & $P$ & Rms error $P$ & Rms error $Y$ \\
\hline OBS & 0.380 & - & 1.92 & - & 0.96 & - \\
CTL & 0.319 & 0.214 & 2.37 & 0.68 & 1.10 & 0.74 \\
LSH & $0.337(54)$ & 0.212 & $2.32(1)$ & 0.65 & $1.11(41)$ & 0.73 \\
\hline
\end{tabular}


TABLE 4. As in Table 2, but for the GCM simulation. (Basins where the statistical significance level is greater than $90 \%$ or $95 \%$ are subscripted with $90 \%$ or $95 \%$, respectively).

\begin{tabular}{|c|c|c|c|c|}
\hline River basin & $\begin{array}{l}\text { OBS flow } \\
\mathrm{mm} \mathrm{day}^{-1}\end{array}$ & $\begin{array}{l}\text { CTRL flow } \\
\text { mm day }{ }^{-1}\end{array}$ & $\begin{array}{l}\text { CTRL-OBS } \\
\text { mm day }{ }^{-1}\end{array}$ & $\begin{array}{l}\text { LSH-OBS } \\
\text { mm day }^{-1}\end{array}$ \\
\hline Amazon $^{+}$ & 2.89 & 2.48 & -0.41 & -0.39 \\
\hline Zaire $^{+}$ & 1.00 & 2.19 & 1.19 & 1.17 \\
\hline Mississippi $_{95 \%}$ & 0.46 & 0.53 & 0.07 & 0.18 \\
\hline $\mathrm{Ob}^{+}$ & 0.37 & 0.30 & -0.07 & -0.03 \\
\hline Yenisei $^{+}$ & 0.63 & 0.37 & -0.26 & -0.23 \\
\hline Lena $_{90 \%}^{+}$ & 0.58 & 0.46 & -0.12 & -0.08 \\
\hline Parana & 0.74 & 1.69 & 0.95 & 1.05 \\
\hline Nile $_{95 \%}$ & 0.13 & 1.15 & 1.02 & 1.16 \\
\hline Amur & 0.48 & 0.39 & -0.09 & -0.11 \\
\hline Chang-Yiang ${ }_{95 \%}^{+}$ & 1.46 & 2.53 & 1.07 & 0.77 \\
\hline Ganges $+\mathrm{B}$. & 1.83 & 1.90 & 0.07 & 0.12 \\
\hline Mackenzie $^{+}$ & 0.50 & 0.71 & 0.21 & 0.18 \\
\hline Volga & 0.51 & 0.49 & -0.02 & -0.05 \\
\hline Nelson $_{95 \%}$ & 0.21 & 0.39 & 0.18 & 0.33 \\
\hline Huango $\mathrm{Ho}^{+}$ & 0.13 & 0.86 & 0.73 & 0.70 \\
\hline Murray & 0.02 & 0.06 & 0.04 & 0.05 \\
\hline Orange & 0.02 & 0.33 & 0.31 & 0.35 \\
\hline Orinoco & 3.20 & 1.73 & -1.47 & -1.47 \\
\hline Indus & 0.41 & 0.78 & 0.37 & 0.42 \\
\hline Danube & 0.69 & 0.68 & -0.01 & 0.02 \\
\hline Yukon & 0.70 & 1.12 & 0.42 & 0.47 \\
\hline Mekong & 1.90 & 1.72 & -0.18 & -0.32 \\
\hline Columbia $^{+}$ & 0.76 & 0.99 & 0.23 & 0.16 \\
\hline $\mathrm{Sao}$ Francisco ${ }^{+}$ & 0.40 & 1.50 & 1.10 & 1.06 \\
\hline Kolyma & 0.53 & 0.55 & 0.00 & 0.02 \\
\hline Niger $_{95 \%}^{+}$ & 1.08 & 0.97 & -0.11 & 0.09 \\
\hline
\end{tabular}

Again the new parameterization tends to increase the runoff per unit precipitation (unless there is a significant reduction in precipitation between the CTL and LSH simulations) (Fig. 5b). The rms errors have again generally improved with the addition of the new scheme, but this is less widespread than in the offline simulations because of the errors in rainfall. There is still an improvement in $Y / P$ bias (from $16 \%$ to $11 \%$ ) and a small reduction in the rms error (Table 3). (The runoff to precipitation ratio changes are found to be statistically significant at the $95 \%$ level over $54 \%$ of grid boxes.)

Table 4 compares the modeled annual mean basin flow with observations. Overall there is less of an improvement with the LSH scheme than in the offline study. As already discussed, this is due to modeled precipitation errors. Only five basin mean flows show statistically significant changes at a $90 \%$ level. [This increases to 11 (not shown) if the $Y / P$ ratio is considered.]

The online estimate of natural wetland (Fig. 3b) is very similar to that in the offline study (Fig. 3a). Overall the coverage seems slightly worse than the offline simulations, indicative of errors in the GCM simulation, in particular the excessive rainfall in central Africa.

\section{c. Climate change}

The zonal mean precipitation generally increases under the simulated climate change (Fig. 6a). The main exception to this is over the southern Tropics, where
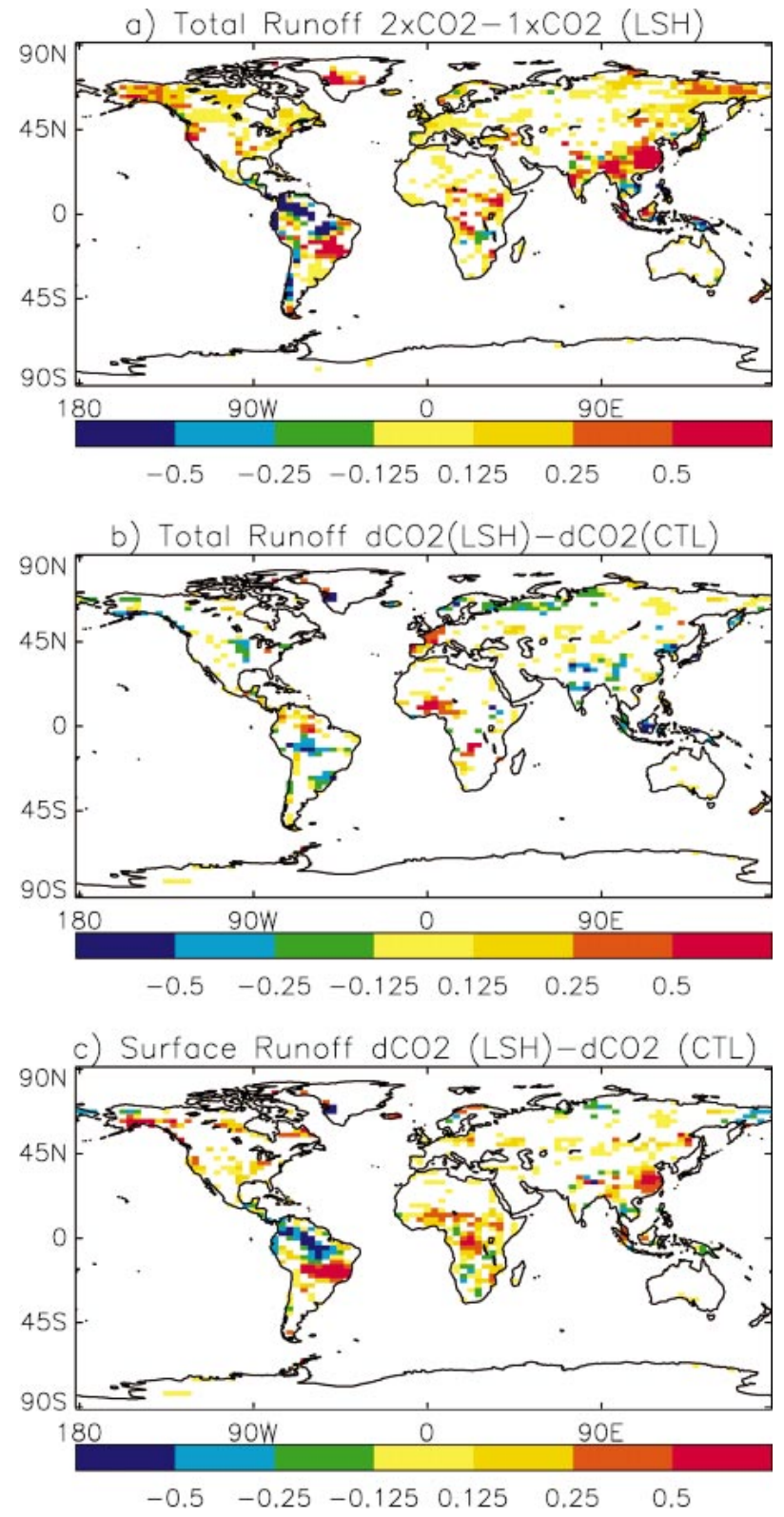

FIG. 7. Annual mean runoff sensitivity to climate change: (a) $2 \times$ $\mathrm{CO}_{2}-1 \times \mathrm{CO}_{2}$ change in the total runoff for LSH. (b), (c) The difference between the sensitivity of the LSH and CTL schemes to climate change for total runoff and surface runoff, respectively. (Only areas where the statistical significance is greater than $95 \%$ are shown.)

there is a dramatic reduction in rainfall over Amazonia (not shown). There is little difference between the predicted precipitation changes with the different LSSs. The total runoff changes (Fig. 6b) tend to follow those of precipitation, again with little difference between the CTL and LSH simulations. An exception to this occurs at around $50^{\circ} \mathrm{N}$. LSH predicts a marked increase in total runoff and CTL changes little. This is because the CTL model simulates a large reduction in surface (Hortonian) runoff, due to thawing at the surface. In the LSH scheme 

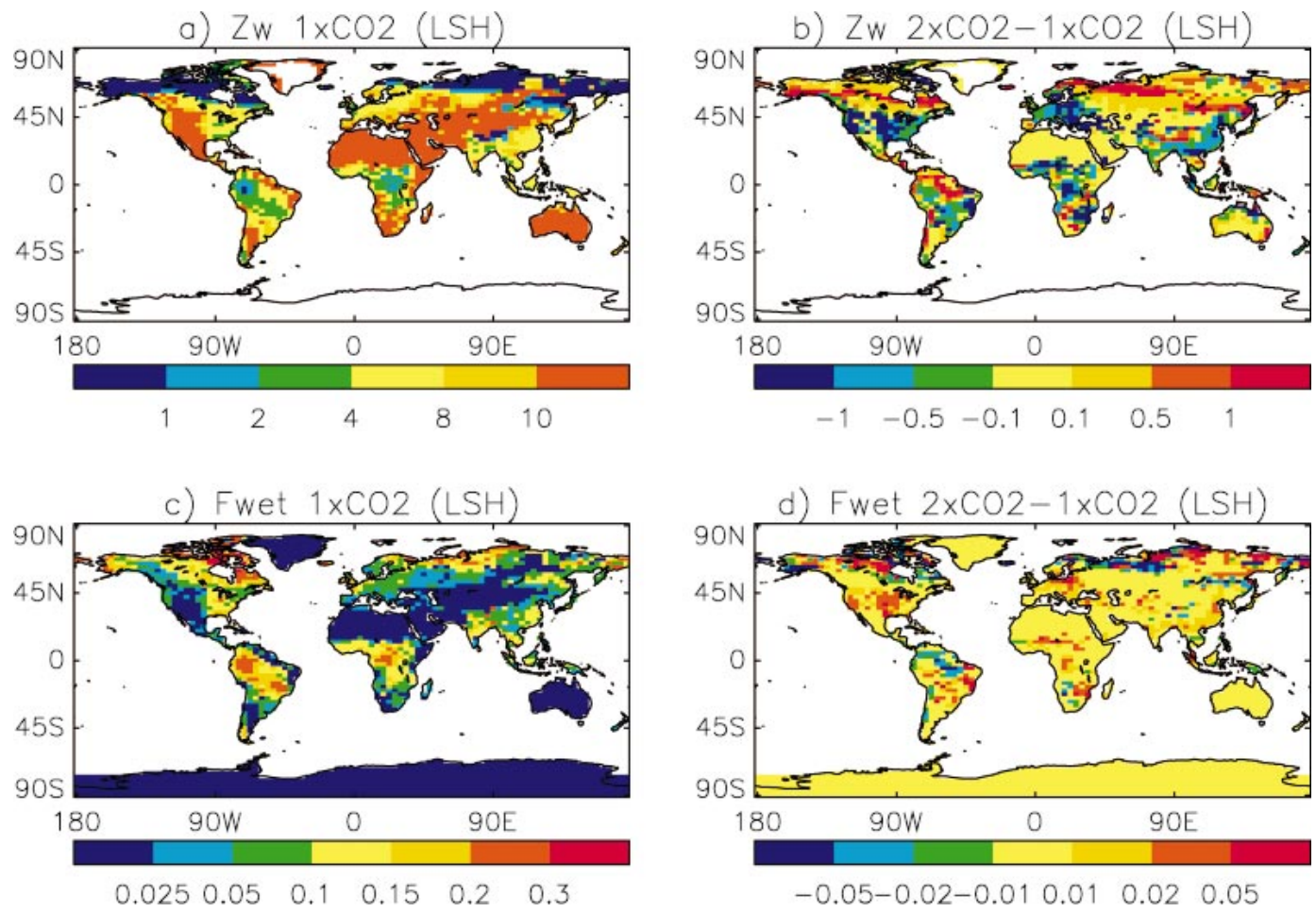

FIG. 8. The $1 \times \mathrm{CO}_{2}$ annual mean LSH simulations and $2 \times \mathrm{CO}_{2}-1 \times \mathrm{CO}_{2}$ change in the annual mean fields:

(a), (b) water table depth (m); (c), (d) total wetland fraction.

there is still significant surface (Dunne) runoff as the water table remains relatively high at $2 \times \mathrm{CO}_{2}$.

However, there are generally large differences between the surface runoff sensitivities (Fig. 6c). Comparing the amplitudes of the predicted geographical changes (Figs. 7a), and the zonal means (Fig. 6), it is clear that much of the change in total runoff from the LSH scheme is due to surface runoff. In addition to the midlatitude differences mentioned previously, the LSH simulation predicts increases in surface runoff over the southern Tropics as the surface saturation increases. However, there is little or no change in the surface runoff in the CTL simulation outside the mid- and high latitudes.

Various annual mean fields that are specific to the LSH scheme are shown in Fig. 8. The tundra regions in the high latitudes and Tropics are clearly depicted with very shallow water tables and extensive wetland areas in the present-day simulation. Under climate change, the water table depth tends to decrease (i.e., a rise in the water table) over those regions where the precipitation increases, and vice versa (see Fig. 6a). The notable exception to this is over high-latitude regions, especially Eurasia. Here the water table falls, in spite of the enhanced precipitation. This is because some of the frozen soil moisture melts, enhancing the drainage through the soil. Changes in the wetland area extent are a result of changes to the mean water table alone when there is no change in frozen soil water content. An in- crease in the water table depth reduces the surface wetland extent, and vice versa. However, over the high latitudes, modifications to the seasonal freeze-thaw cycle may complicate the annual mean wetland response.

\section{Conclusions}

We have adapted the MOSES GCM land surface scheme to represent the dependence of subgrid soil moisture on topography, using ideas from TOP MODEL (Beven and Kirkby 1979). This involved introducing a mean water table within the MOSES soil model, and applying a high-resolution global dataset of the topographic index to diagnose the subgrid variation in this water table.

The revised large-scale hydrology (LSH) scheme improves the simulation of runoff in both offline simulations (driven by observations) and online simulations (coupled to the atmospheric GCM). In both cases the rms error and global mean bias of annual mean total runoff to precipitation ratio are reduced. When coupled to the GCM, the new model also improves the simulation of the annual mean precipitation.

The subgrid-scale distribution of water table depths can be used to estimate the saturated fraction of each grid box, and thereby the wetland extent. This simple approach is able to reproduce most of the major wetland regions across the globe. Further improvements should be possible by including a dependence of the vertical 
variation of the saturated soil conductivity on soil carbon content.

The LSH scheme also influences the GCM sensitivity to doubling $\mathrm{CO}_{2}$. Outside the midlatitudes the surface runoff is much more sensitive to climate change in the LSH scheme. Over the midlatitudes the LSH model produces a significant increase in total runoff, whereas no such signal is evident when the standard CTL model is used. The difference can be traced to the dominant mechanisms for generating surface runoff. In the standard MOSES model surface runoff is generated mainly from frozen soils with low permeability, but in the LSH scheme the subgrid-scale soil moisture allows surface runoff generation from locally saturated soils (by the Dunne mechanism). Under climate warming many seasonally frozen soils become ice-free all year around, and this reduces midlatitude surface runoff significantly in the standard MOSES model. (The area where the ratio of annual mean frozen to total soil moisture ratio is greater than 0.01 drops by $8 \%$ in the $2 \times \mathrm{CO}_{2}$ run.) Surface runoff is far less dependent on soil freezing in LSH, which therefore produces less significant changes in total runoff.

Gedney et al. (2000) demonstrate that the runoff parameterization is the primary cause of the systematic runoff underestimate in the standard MOSES model. Even though this bias is reduced considerably when the effect of local topography on soil moisture is included, there is still a systematic underestimate in the model. Further work is required to address the need to include other causes of soil moisture heterogeneity, such as subgrid-scale variation in soil properties and vegetation. Incorporating the effect of soil carbon content on vertical soil properties also needs further investigation.

The broad findings of this paper are consistent with the view that the representation of the land surface largely determines the projected hydrological impacts under climate change (Gedney et al. 2000). Any improvement to the representation of subgrid soil moisture heterogeneity, such as that presented here, can be seen as a vital step towards producing useful hydrological impacts assessments online within the GCM, thereby producing internally consistent projections of climate and hydrological changes.

Acknowledgments. We would like to thank the UK Department for Environment, Food and Rural Affairs for support through Contract PECD 7/12/37.

\section{REFERENCES}

Aselmann, I., and P. Crutzen, 1989: Global distribution of natural freshwater wetlands and rice paddies, their net primary productivity, seasonality and possible methane emissions. J. Atmos. Chem., 8, 307-358.

Beven, K., 1982: On subsurface stormflow, an analysis of response times. Hydrol. Sci. J., 27, 505-521.
_ 1986: Runoff production and flood frequency in catchments of order n: An alternative approach. Scale Problems in Hydrology, V. K. Gupta et al., Eds., Kluwer, 107-131.

—_ and M. Kirkby, 1979: A physically based, variable contributing area model of basin hydrology. Hydrol. Sci. Bull., 24, 43-69.

Boone, A., and P. J. Wetzel, 1999: A simple scheme for modeling sub-grid soil texture variability for use in an atmospheric climate model. J. Meteor. Soc. Japan, 77, 317-333.

Brown, S. R., and C. H. Scholz, 1985: Broad bandwidth study of the topography of natural rock surfaces. J. Geophys. Res., 90 (B14), $2575-2582$.

Clapp, R., and G. Hornberger, 1978: Empirical equations for some soil hydraulic properties. Water Resour. Res., 14, 601-604.

Cox, P. M., R. A. Betts, C. B. Bunton, R. L. H. Essery, P. R. Rowntree, and J. Smith, 1999: The impact of new land surface physics on the GCM simulation of climate and climate sensitivity. Climate Dyn., 15, 183-203.

de Rosnay, P., J. Polcher, M. Bruen, and K. Laval, 2002: Impact of a physically based soil water flow and soil-plant interaction representation for modeling large-scale land surface processes. J. Geophys. Res., 107, 4118, doi:10.1029/2001JD000634.

Dirmeyer, P., A. Dolman, and N. Sato, 1999: The pilot phase of the Global Soil Wetness Project. Bull. Amer. Meteor. Soc., 80, 851878.

Dumenil, L., and E. Todini, 1992: A rainfall-runoff scheme for use in the Hamburg climate model. Advances in Theoretical Hydrology -A Tribute to James Dooge, J. P. O'Kane, Ed., Elsevier, 129-157.

Essery, R. L. H., M. J. Best, R. A. Betts, P. M. Cox, and C. M. Taylor, 2003: Explicit representation of subgrid heterogeneity in a GCM land surface scheme. J. Hydrometeor., 4, 530-543.

Fekete, B. M., C. J. Vorosmarty, and W. Grabs, 2002: High-resolution fields of global runoff combining observed river discharge and simulated water balances. Global Biogeochem. Cycles, 16, 1042, doi:10.1029/1999GB001254.

Gates, W., 1992: AMIP: The Atmospheric Model Intercomparison Project. Bull. Amer. Meteor. Soc., 73, 1962-1970.

Gedney, N., P. Cox, H. Douville, J. Polcher, and P. Valdes, 2000: Characterizing GCM land surface schemes to understand their responses to climate change. J. Climate, 13, 3066-3079.

Houghton, J. T., Y. Ding, D. J. Griggs, M. Noguer, P. J. vander Linden, and D. Xiaosu, Eds., 2001: Climate Change 2001: The Scientific Basis. Contribution of Working Group I to the Third Assessment Report of the Intergovernmental Panel on Climate Change. Cambridge University Press, $881 \mathrm{pp}$.

Koster, R. D., and M. J. Suarez, 1992: Modeling the land surface boundary in climate models as a composite of independent vegetation stands. J. Geophys. Res., 97 (D3), 2697-2715.

Mitchell, J. F. B., T. C. Johns, J. M. Gregory, and S. F. B. Tett, 1995: Climate response to increasing levels of greenhouse gases and sulphate aerosols. Nature, 376, 501-504.

Moore, R., 1985: The probability distributed principle and runoff production at point and basin scales. Hydrol. Sci. J., 30, 273297.

Polcher, J., and Coauthors, 2000: GLASS: Global Land Atmosphere System Study. GEWEX News, 10, 3-5.

Pope, V. D., M. L. Gallani, P. R. Rowntree, and R. A. Stratton, 2000: The impact of new physical parameterizations in the Hadley Centre climate model-HadAM3. Climate Dyn., 16, 123-146.

Sivapalan, M., K. Beven, and E. Wood, 1987: On hydrological similarity. 2. A scaled model of storm runoff production. Water Resour. Res., 23, 2266-2278.

Stieglitz, M., D. Rind, J. Famigletti, and C. Rosenzweig, 1997: An efficient approach to modeling the topographic control of surface hydrology for regional and global climate modeling. J. Climate, 10, 118-137.

UNESCO, 1971: Discharge of Selected Rivers of the World. Studies and Reports in Hydrology, Vol. 2, UNESCO, 194 pp. 
Verdin, K. L., and S. Jensen, 1996: Development of continental scale digital elevation models and extraction of hydrographic features. Proc. Third Int. Conf. Workshop on Integrating GIS and Environmental Modeling. Santa Barbara, CA, National Center for Geographic Information and Analysis.

Wood, E. F., D. P. Lettenmaier, and V. G. Zartarian, 1992: A land- surface hydrology parameterization with subgrid variability for general circulation models. J. Geophys. Res., 97, 2717-2728.

Xie, P., and P. A. Arkin, 1997: Global precipitation: A 17-year monthly analysis based on gauge observations, satellite estimates, and numerical model outputs. Bull. Amer. Meteor. Soc., 78, 25392558 . 